Correction

\title{
Correction: Z. Liu and Y. Liu. Does Anthropogenic Land Use Change Play a Role in Changes of Precipitation Frequency and Intensity over the Loess Plateau of China? Remote Sens. 2018, 10, 1818
}

\author{
Zhengjia Liu ${ }^{1,2,3, *}$ and Yansui Liu ${ }^{1,3, *}$ \\ 1 Institute of Geographic Sciences and Natural Resources Research, Chinese Academy of Sciences, \\ Beijing 100101, China \\ 2 State Key Laboratory of Remote Sensing Science, Institute of Remote Sensing and Digital Earth, Chinese \\ Academy of Sciences, Beijing 100101, China \\ 3 College of Resources and Environment, University of Chinese Academy of Sciences, Beijing 100049, China \\ * Correspondence: 1zj7sdjn@126.com (Z.L.); liuys@igsnrr.ac.cn (Y.L.); Tel.: +86-186-1261-2470 (Z.L.)
}

Received: 28 June 2019; Accepted: 2 July 2019; Published: 5 July 2019

check for updates

The original version of the paper [1] incorrectly presents Figure $2 b$ (a land use change map from the year 2000 to the year 2010) and corresponding statistical information in Section 3.1 of the main text. The mistake was caused by pixel skewing when one used the mask to extract land use map, which led to the land use map (for the year 2010) of the entire study area moving a pixel to the left. Here we intend to correct Figure $2 \mathrm{~b}$ and the corresponding statistical information in Section 3.1 of the main text.

\section{Partial Corrections of Section 3.1}

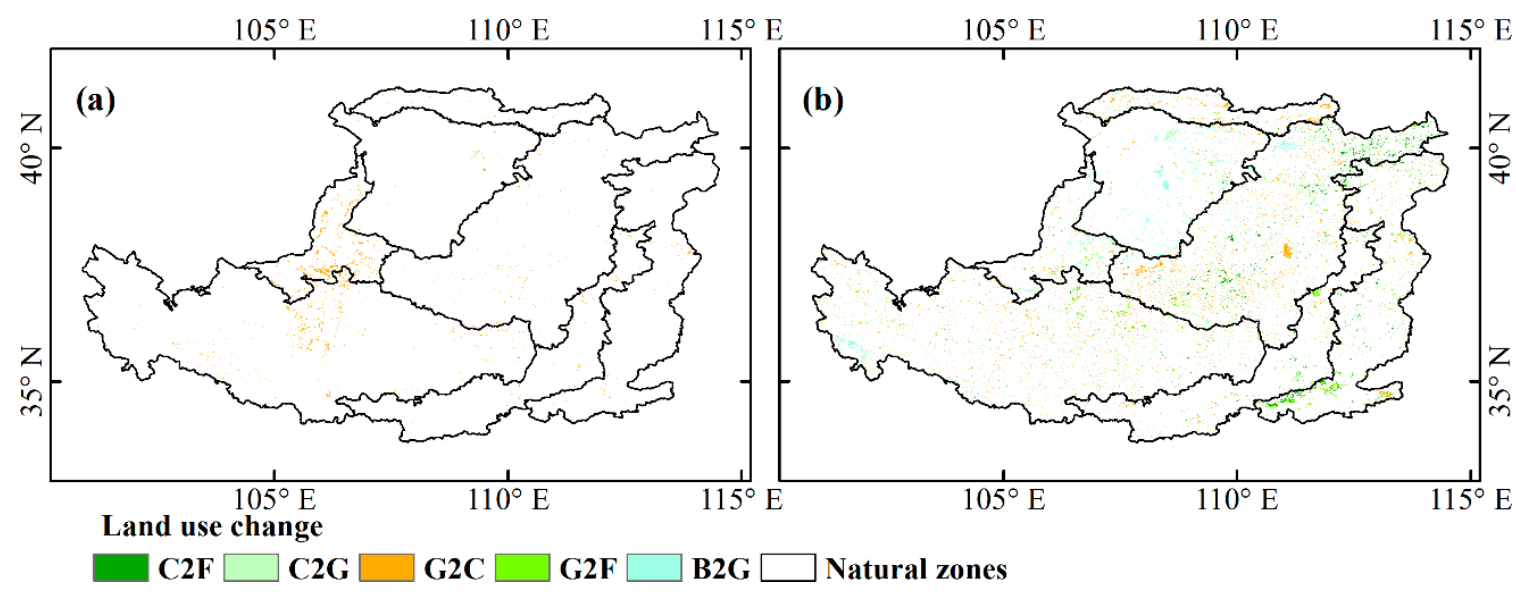

Figure 2. Major land use changes, with overall change area being greater than $0.5 \%$ of the entire study area during the periods 1990-1999 (a) and 2000-2010 (b). C2F represents conversion from croplands to forests; $\mathrm{C} 2 \mathrm{G}$ represents conversion from croplands to grasslands; $\mathrm{G} 2 \mathrm{C}$ represents conversion from grasslands to croplands; G2F represents conversion from grasslands to forests; and B2G represents conversion from barren or sparsely vegetated land to grasslands.

After the year 2000, larger land use changes were observed across the entire Loess Plateau, but these land use conversions were very fragmented (Figure $2 \mathrm{~b})$. The increase in forests $(+0.71 \%)$ and urban and built-up land $(+0.50 \%)$ and the decrease in croplands $(-0.71 \%)$, barren or sparsely vegetated lands $(-0.32 \%)$, and grasslands $(-0.22 \%)$ were major land use dynamics in the Loess Plateau. Specifically, in the land use dynamic process, conversion from croplands to grasslands and conversion 
from grasslands to croplands were major land use change types, accounting for $1.52 \%$ and $1.51 \%$ of the entire study area, respectively. The second were conversion from grasslands to forests, conversion from barren or sparsely vegetated lands to grasslands, and conversion from croplands to forests, accounting for $0.74 \%, 0.73 \%$ and $0.57 \%$, respectively. One can see that land conservation dominated land use dynamics in the context of the 'Grain for Green' project [11,57]. In addition, there are also some regions with grassland degeneration $(0.47 \%$, mainly located in the northwestern Loess Plateau; the Mu Us Sandy Land). Please note that urban expansion mainly occupied croplands around urban and build-up land $(0.40 \%)$.

The main experimental results presented and the conclusions of the paper are not affected by these changes. We apologize for any inconvenience caused to readers.

\section{References}

1. Liu, Z.; Liu, Y. Does Anthropogenic Land Use Change Play a Role in Changes of Precipitation Frequency and Intensity over the Loess Plateau of China? Remote Sens. 2018, 10, 1818. [CrossRef]

(C) 2019 by the authors. Licensee MDPI, Basel, Switzerland. This article is an open access article distributed under the terms and conditions of the Creative Commons Attribution (CC BY) license (http://creativecommons.org/licenses/by/4.0/). 